\title{
A prospective, randomized study of Toremifene vs. tamoxifen for the treatment of premenopausal breast cancer: safety and genital symptom analysis
}

Jin Hong ${ }^{\dagger}$, Jiahui Huang ${ }^{\dagger}$, Lili Shen, Siji Zhu, Weiqi Gao, Jiayi Wu, Ou Huang, Jianrong He, Li Zhu, Weiguo Chen, Yafen Li, Xiaosong Chen ${ }^{\dagger}$ and Kunwei Shen ${ }^{*}$ (i)

\begin{abstract}
Background: Toremifene (TOR) is a selective oestrogen receptor modulator (SERM) and has comparable efficacy to that of tamoxifen (TAM) in breast cancer patients. Herein, we compared the safety of TOR to that of TAM in the adjuvant treatment of premenopausal breast cancer.

Methods: This was a prospective randomized and open-label clinical study. Premenopausal patients with hormonal receptor (HR)-positive early breast cancer were randomly assigned (1:1) to receive TOR) or TAM treatment. The follow-up period was 1 year. The primary end point was the incidence of ovarian cysts, and secondary end points were the incidence of endometrial thickening, changes in female hormones, the incidence of fatty liver, changes in the modified Kupperman index (mKMl) and changes in quality of life.

Results: There were 92 patients in the final analysis. The incidences of ovarian cysts were $42.6 \%$ in the TOR group and $51.1 \%$ in the TAM group $(p=0.441)$. Forty-one patients $(87.2 \%)$ in the TOR group and 36 patients $(80.0 \%)$ in the TAM group experienced endometrial thickening $(p=0.348)$. The proportions of patients with fatty liver were $31.9 \%$ in the TOR group and $26.7 \%$ in the TAM group $(p=0.581)$. No significant differences in the mKMl or quality of life were observed between the two groups.
\end{abstract}

Conclusions: TOR and TAM have similar side effects on the female genital system and quality of life in premenopausal early breast cancer patients.

Trial registration: ClinicalTrials.gov NCT02344940. Registered 26 January 2015 (retrospectively registered).

Keywords: Toremifene, Tamoxifen, Breast cancer, Premenopausal patients, Safety, Quality of life

\footnotetext{
* Correspondence: kwshen@medmail.com.cn

†Jin Hong, Jiahui Huang and Xiaosong Chen contributed equally to this work.

Department of General Surgery, Comprehensive Breast Health Center, Ruijin Hospital, Shanghai Jiao Tong University School of Medicine, 197 Ruijin Second Road, Shanghai 200025, China
}

(c) The Author(s). 2020 Open Access This article is licensed under a Creative Commons Attribution 4.0 International License, which permits use, sharing, adaptation, distribution and reproduction in any medium or format, as long as you give appropriate credit to the original author(s) and the source, provide a link to the Creative Commons licence, and indicate if changes were made. The images or other third party material in this article are included in the article's Creative Commons licence, unless indicated otherwise in a credit line to the material. If material is not included in the article's Creative Commons licence and your intended use is not permitted by statutory regulation or exceeds the permitted use, you will need to obtain permission directly from the copyright holder. To view a copy of this licence, visit http://creativecommons.org/licenses/by/4.0/ The Creative Commons Public Domain Dedication waiver (http://creativecommons.org/publicdomain/zero/1.0/) applies to the data made available in this article, unless otherwise stated in a credit line to the data. 


\section{Background}

Endocrine therapy is a primary systemic therapy for hormonal receptor (HR)-positive breast cancer. Tamoxifen (TAM) is a selective oestrogen receptor modulator (SERM) that competitively inhibits oestrogen binding to oestrogen receptor (ER) and is effective in both pre- and postmenopausal women [1]. A meta-analysis showed that compared with no endocrine therapy, adjuvant TAM for 5 years reduced the 5 -year breast cancer recurrence rate by approximately $50 \%$ in HR-positive breast cancer [2]. A longer duration of TAM has also been suggested for specific premenopausal breast cancer patients [3, 4].

However, TAM often causes a range of adverse events, such as hot flashes, endometrial hyperplasia or uterine cancer, ovarian cyst formation and thromboembolic disease $[1,5,6]$. Hot flashes are the most common side effect, affecting approximately $42.9 \%$ of patients taking TAM [7]. Ovarian cysts are diagnosed in $17-19 \%$ of patients treated with TAM, and in premenopausal women, the proportion of ovarian cysts varies from 30 to $49 \%[6,8]$. There is little risk of endometrial cancer in patients younger than 54 years [2]. Additionally, TAM causes other adverse events, such as fatty liver and lipid changes $[9,10]$.

Toremifene (TOR) is another SERM option for the treatment of HR-positive breast cancer and differs from TAM in structure by only one chlorine atom [11]. In postmenopausal patients, TOR has been verified to have similar efficacy to that of tamoxifen as an adjuvant treatment and for metastatic disease [11-14]. In contrast to TAM, which is metabolized by cytochrome $\mathrm{P} 450$ enzymes, TOR is not a prodrug and has better efficacy in breast cancer patients with the CYP2D6*10 T/T genotype [15]. Data on the efficacy of TOR in premenopausal patients are limited. A retrospective study revealed that TOR had a 5-year overall survival rate that was similar to that of TAM and an even better recurrence-free survival rate than that of TAM [16]. To date, there are no data regarding comparisons of the side effects of TOR versus TAM in premenopausal breast cancer patients. Herein, we carried out a prospective clinical study to evaluate the safety of TOR versus TAM in premenopausal patients with early breast cancer.

\section{Methods}

\section{Study design and treatment}

This was a prospective, single-centre, randomized, controlled, and open-label clinical study. All participants were from Ruijin Hospital, Shanghai Jiao Tong University, School of Medicine. Premenopausal patients with HR-positive early breast cancer who were scheduled to receive SERMs as adjuvant endocrine therapy after discussion by the multidisciplinary team (MDT) were recruited. A block randomization method with a block size of 6 was used to achieve balance between treatment groups by the investigator. There was no stratification for the study. Patients were enrolled by doctors in our centre. Sequentially numbered opaque sealed envelopes were used for allocation concealment and managed by the oncology nurse specialist.

After surgery, chemotherapy, and radiotherapy, patients were randomly assigned at a $1: 1$ ratio to the TOR group and the TAM group. Patients in the TOR group received TOR citrate tablets $(60 \mathrm{mg} /$ day $)$, and patients in the TAM group received TAM citrate tablets $(20 \mathrm{mg} /$ day). All patients were followed up every 3 months in the first year from endocrine therapy initiation.

\section{Eligibility criteria}

Patients were included if they met the following criteria: were premenopausal women; had histologically confirmed HR-positive breast cancer; underwent standard surgery for breast cancer; had completed other adjuvant therapy, such as chemotherapy and radiotherapy; had leukocyte counts $\geq 3.0 \times 10^{9} / \mathrm{L}$ and platelet counts $\geq 75 \times$ $10^{9} / \mathrm{L}$; had serum alanine aminotransferase (ALT) or aspartate aminotransferase (AST) levels that were $\leq 2.5$ times the upper limit of normal range (ULN); had serum creatinine levels less than the ULN; and had an Eastern Cooperative Oncology Group (ECOG) performance score of $0-2$. The exclusion criteria were as follows: HR negative; previous neoadjuvant or adjuvant endocrine therapy administration; metastatic malignancies; family history of endometrial cancer or other gynaecologic malignant tumours; ovarian cysts (largest diameter $\geq 2 \mathrm{~mm}$ ) by transvaginal ultrasound (TVU); hysterectomy or ovariectomy surgery; any complication that increased sex hormone secretion, such as thymic cancer, ovarian tumour or pituitary adenoma; any complication that decreased sex hormone secretion, such as hyperthyroidism, hypothyroidism, severe malnutrition, liver cirrhosis, sex hormone synthetase deficiency, Turner's syndrome, intracranial tumour, or a pituitary condition; a severe non-malignant comorbidity that could influence longterm follow-up; severe cardiac dysfunction; severe hepatic dysfunction, Child-Pugh $\mathrm{C}$; or a known severe hypersensitivity to any drug in this study.

\section{Clinicopathological information}

The patients' clinical information was collected from the case report forms of the study. Medical history data included age, menstrual status, ECOG score, past medical history, biochemical parameters and the parameters of routine blood tests. Other treatment information included chemotherapy, radiotherapy, and targeted therapy. Pathological results were reported by two different pathologists independently and included pathological type, tumour size, histological grade, lymph node involvement, ER expression, progesterone receptor (PR) 
expression, CerbB-2 status and the result of the fluorescence in situ hybridization (FISH) test. ER or PR positivity was defined as nuclear staining in more than $1 \%$ of tumour cells. Tumours with a CerbB-2 $3+$ status in the immunohistochemistry assay and/or human epidermal growth factor receptor-2 (HER-2) gene overexpression confirmed by FISH were defined as HER-2 positive.

Serum oestradiol (E2), follicle-stimulating hormone (FSH) and luteinizing hormone (LH) were measured at baseline and every 3 months after randomization by the gynecological clinical Lab in our hospital. Hormone levels were analyzed using commercially available kits from the Unicel DXI 800 Access immunoassay system (Beck-man Coulter).

\section{Study end points}

The primary end point of the study was the incidence of ovarian cysts, which were defined as pure liquid-filled structures that were equal to or greater than $2.0 \mathrm{~cm}$ at their largest diameters by TVU. The secondary end points were as follows: the incidence of endometrial thickening (endometrium $\geq 8.0 \mathrm{~mm}$ measured by TVU), changes in female hormones (E2, FSH and LH), the incidence of fatty liver (detected by abdominal ultrasound according to the criteria of the American Association for the Study of Liver Disease [17]), changes in the modified Kupperman Menopausal index (mKMI) and changes in quality of life.

\section{Assessment of menopausal symptoms}

The mKMI was used to evaluate menopausal symptoms [18]. The mKMI consists of 13 items: hot flashes/sweats, palpitation, vertigo, headache, paraesthesia, formication, arthralgia, myalgia, fatigue, nervousness, melancholia, urinary infections and sexual complaints. Each item was divided into four grades ( $0-3$ points) according to severity: 0 , no symptoms; 1 , mild symptoms; 2 , moderate symptoms; and 3 , severe symptoms. The total scores ranged from 0 to 63 , and score ranges of $0-6,7-15,16-$ 30 and $>30$ represented the degrees of severity, namely, none, mild, moderate and severe, respectively [18]. Patients were asked to complete the mKMI questionnaire at baseline and then every 3 months.

\section{Quality of life assessment}

Quality of life was assessed using the European Organization for Research and Treatment of Cancer (EORTC) QLQ-C30 (version 3.0), which consists of 30 questions addressing five functional scales (cognitive, emotional, physical, social, and role), nine symptom scales (appetite loss, constipation, diarrhoea, dyspnoea, fatigue, financial difficulties, insomnia, nausea and vomiting, and pain) and one global health status scale [19]. The EORTC-QLQ-C30 questionnaires were completed at baseline and then every 6 months.

\section{Statistical analysis}

The study was designed to have a power of $90 \%$ to detect an absolute reduction of $20 \%$ for the incidence of ovarian cysts in patients treated with toremifene compared to patients treated with tamoxifen (15\% vs $35 \%)$, at a one-sided significance level of 0.05 . Taking a withdrawal rate of $15 \%$ into consideration, the target enrolment was 52 eligible patients for each group based on the Simon 2-stage design.

Categorical variables between two groups are presented as frequencies and percentages and were compared using chi-square tests (the 2-sided Pearson) or Fisher's exact test. Continuous data are presented as the mean \pm standard deviation (SD) or mean \pm standard error (SE) and were compared using a nonparametric test (Mann-Whitney U). The analysis was performed using SPSS (version 22.0) software (IBM Corporation, Armonk, NY, USA), and figures were generated by GraphPad Prism (version 5) (GraphPad Software, San Diego, CA, USA). A $p$ value $<0.05$ was considered to indicate statistical significance.

\section{Results \\ Study population}

From December 2014 to June 2017, 104 patients were recruited and randomized to receive either toremifene $(N=52)$ or tamoxifen $(\mathrm{N}=52)$ treatment. Twelve patients did not receive the study drugs: one suffered from a severe rash in the toremifene group, two received nonstudy drugs due to personal reasons, and nine were lost to follow-up (Fig. 1). Finally, a total of 92 patients were collected in the final analysis.

The patients' clinicopathological characteristics and adjuvant treatments were well balanced between the two groups (Table 1). The median ages were 45 years in the TOR group and 44 years in the TAM group. Regarding the tumours of these patients, $78.3 \%$ were invasive ductal carcinomas, and 7 were ductal carcinomas in situ. Eighty-one patients had stage I or II breast cancer. Immunohistochemistry showed that 86 (93.5\%) tumours were more than $50 \%$ ER positive, that $69(75 \%)$ tumours were more than $20 \%$ PR positive, and that only 6 patients were HER-2 positive. Regarding adjuvant treatment, 33 patients received chemotherapy, 44 patients received radiotherapy, and 4 patients received trastuzumab treatment. All patients were menstruating before surgery, 6 patients in the TOR group and 10 patients in the TAM group had chemotherapy induced amenorrhea.

\section{Incidence of ovarian cyst formation}

After 1 year of follow-up every 3 months, 20 patients (42.6\%) in the TOR group and 23 patients (51.1\%) in the TAM group had ovarian cysts (largest diameter $\geq 2.0 \mathrm{~cm}$ ) detected by TVU (Fig. 2a). The mean values of the 


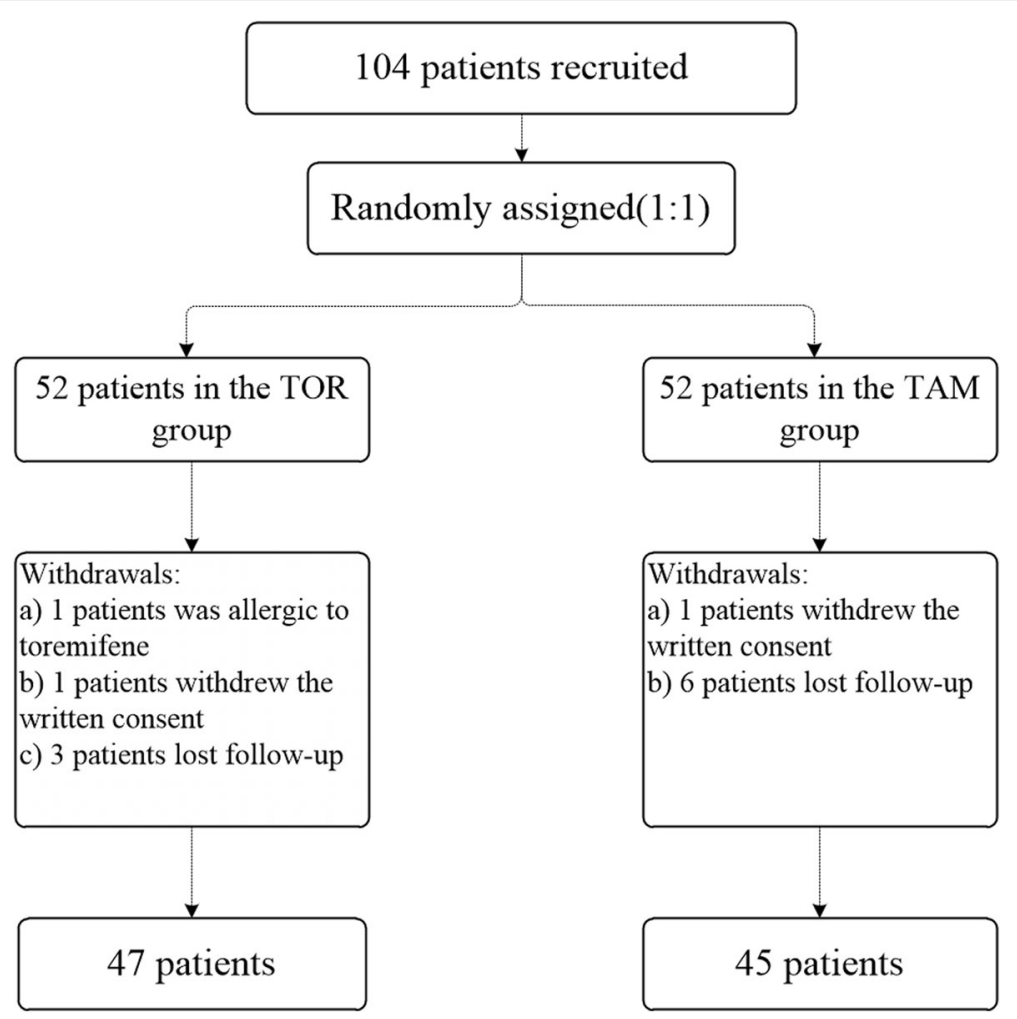

Fig. 1 Flow Chart of Patient's Enrollment

ovarian cyst diameters were $3.62 \pm 1.27 \mathrm{~cm}$ in the TOR group and $3.75 \pm 1.50 \mathrm{~cm}$ in the TAM group (Fig. 2b, $p=0.789)$. There was no significant difference in the incidence of ovarian cysts between the two groups $(\mathrm{OR}=$ $1.411,95 \% \mathrm{CI}=0.620-3.211, p=0.441)$.

The percentages of ovarian cysts (largest diameter $\geq$ $3.0 \mathrm{~cm}$ ) were $27.7 \%$ in the TOR group and $37.8 \%$ in the TAM group, and there was no significant difference between the two groups $(\mathrm{OR}=1.588,95 \% \mathrm{CI}=0.660$ $3.822, p=0.301)$.

\section{Incidence of endometrial thickening}

The incidences of endometrial thickening in premenopausal patients treated with toremifene and tamoxifen are shown in Fig. 2c. The mean endometrial thicknesses were $12.00 \pm 2.98 \mathrm{~mm}$ in the toremifene group and $11.80 \pm 2.91$ $\mathrm{mm}$ in the tamoxifen group (Fig. $2 \mathrm{~d}, p=0.723$ ). Forty-one patients $(87.2 \%)$ in the TOR group and 36 patients (80.0\%) in the TAM group had endometrial thickening (endometrium $\geq 8.0 \mathrm{~mm}$ ) during the one-year follow-up period. No significant difference in the incidence of endometrial thickening was observed between the two groups $(\mathrm{OR}=0.585,95 \% \mathrm{CI}=0.190-1.805, p=0.348)$.

\section{Changes in plasma FSH, $\mathrm{LH}$, and E2 concentrations}

Among 92 patients, 23 in the TOR group and 17 in the TAM group had complete serum E2, FSH, and LH data at each follow-up. The mean values for E2, FSH and LH at each follow-up in the two groups are presented in supplementary Table 1. Figure 3a shows the mean E2 value. At baseline, the mean E2 values were $102.96 \mathrm{pg} / \mathrm{L}$ in the TOR group and $88.24 \mathrm{pg} / \mathrm{L}$ in the TAM group. This concentration increased to $262.39 \mathrm{pg} / \mathrm{L}$ at the 9th month of toremifene treatment. In the TAM group, the mean E2 level increased to $238.12 \mathrm{pg} / \mathrm{L}$ at the 3rd month and decreased thereafter. The mean E2 values at the 9th month $(p=0.042)$ and 12th month $(p=0.018)$ were significantly higher in the TOR group than in the TAM group. The mean values for FSH and $\mathrm{LH}$ were in the normal range at each follow-up exam. There were no significant differences between the two groups.

\section{Incidence of fatty liver}

Fifteen of 47 patients in the TOR group and 12 of 45 patients in the TAM group developed fatty liver during one year of endocrine therapy. There was no significant difference between the two groups $(31.9 \%$ vs $26.7 \%$, $\mathrm{OR}=0.776,95 \% \mathrm{CI}=0.315-1.911, p=0.581)$.

\section{Assessment of menopausal symptoms and quality of life}

The numbers of patients who completed the mKMI questionnaire and the mean mKMI scores of the two groups at baseline and for every 3 months of follow-up are listed in Table 2. There were no significant 
Table 1 Baseline Patient characteristics and treatment

\begin{tabular}{|c|c|c|c|c|}
\hline \multirow[t]{2}{*}{ Characteristic } & \multirow[t]{2}{*}{ Overall, n(\%) } & \multicolumn{2}{|c|}{ Groups } & \multirow[t]{2}{*}{$p$-value } \\
\hline & & TOR & TAM & \\
\hline Age & & & & 0.053 \\
\hline$<40$ & $12(13.0)$ & 3 & 9 & \\
\hline$\geq 40$ & $80(87.0)$ & 44 & 36 & \\
\hline $\mathrm{BMI}$ & & & & 0.880 \\
\hline$<24$ & 73(79.3) & 37 & 36 & \\
\hline$\geq 24$ & 19(20.7) & 10 & 9 & \\
\hline Surgery & & & & 0.273 \\
\hline Mastectomy & $54(58.7)$ & 25 & 29 & \\
\hline $\mathrm{BCS}$ & $38(41.3)$ & 22 & 16 & \\
\hline Pathology & & & & 0.890 \\
\hline IDC & 72(78.3) & 37 & 35 & \\
\hline DCIS & $7(7.6)$ & 4 & 3 & \\
\hline Others & $13(14.1)$ & 6 & 7 & \\
\hline Tumors & & & & 0.717 \\
\hline$\leq 2.0 \mathrm{~cm}$ & $67(72.8)$ & 35 & 32 & \\
\hline$>2.0 \mathrm{~cm}$ & $25(27.2)$ & 12 & 13 & \\
\hline Nodes status & & & & 0.830 \\
\hline Negative & 79(85.9) & 40 & 39 & \\
\hline Positive & 13(14.1) & 7 & 6 & \\
\hline Grade & & & & 0.655 \\
\hline 1 & 15(16.3) & 9 & 6 & \\
\hline$\|$ & $47(51.1)$ & 25 & 22 & \\
\hline III & $11(12.0)$ & 4 & 7 & \\
\hline NA & 19(20.7) & 9 & 10 & \\
\hline ER & & & & 0.430 \\
\hline$\geq 50 \%$ & 86(93.5) & 43 & 43 & \\
\hline$<50 \%$ & $6(6.5)$ & 4 & 2 & \\
\hline PR & & & & 0.399 \\
\hline$\geq 20 \%$ & $69(75)$ & 37 & 32 & \\
\hline$<20 \%$ & $23(25)$ & 10 & 13 & \\
\hline HER-2 & & & & 0.430 \\
\hline positive & $6(6.5)$ & 4 & 2 & \\
\hline negative & 86(93.5) & 43 & 43 & \\
\hline Subtype & & & & 0.164 \\
\hline Luminal A like & $40(43.5)$ & 24 & 16 & \\
\hline Luminal B HER2 negative & $46(50.0)$ & 19 & 27 & \\
\hline Luminal B HER2 positive & $6(6.5)$ & 4 & 2 & \\
\hline Ki67 & & & & 0.554 \\
\hline$<14 \%$ & $58(63.0)$ & 31 & 27 & \\
\hline$\geq 14 \%$ & $34(37.0)$ & 16 & 18 & \\
\hline Chemotherapy & & & & 0.709 \\
\hline Yes & 33(35.9) & 16 & 17 & \\
\hline No & $59(64.1)$ & 31 & 28 & \\
\hline
\end{tabular}


Table 1 Baseline Patient characteristics and treatment (Continued)

\begin{tabular}{|c|c|c|c|c|}
\hline \multirow[t]{2}{*}{ Characteristic } & \multirow[t]{2}{*}{ Overall, n(\%) } & \multicolumn{2}{|c|}{ Groups } & \multirow[t]{2}{*}{$p$-value } \\
\hline & & $\mathrm{TOR}$ & TAM & \\
\hline Radiotherapy & & & & 0.828 \\
\hline Yes & $44(47.8)$ & 23 & 21 & \\
\hline No & $48(52.2)$ & 24 & 24 & \\
\hline Trastuzumab & & & & 0.328 \\
\hline Yes & $4(4.3)$ & 3 & 1 & \\
\hline No & $88(95.7)$ & 44 & 44 & \\
\hline
\end{tabular}

Abbreviations: BMI Body Mass Index, IDC Invasive ductal carcinoma, DCIS Ductal carcinoma in situ, NA Not available, BCS Breast conserving surgery, ER Estrogen receptor, $P R$ Progestrone receptor, TAM Tamoxifen, TOR Toremifene

${ }^{*} p<0.05$ was considered statistically significant

differences in the mean mKMI scores between the TOR group and the TAM group at each follow-up. The highest mean mKMI score was 13.00 at the 6th month in the TOR group and 13.03 at the 9th month in the TAM group.

The EORTC-QLQ-C30 questionnaire was used to assess quality of life. The mean scores of the functional scales and symptom scales were compared between the TOR group and TAM group. There were no significant differences in any scale between the two groups throughout follow-up (Table 3). The mean scores of all functional scales increased gradually except for the mean score of cognitive functioning, which decreased from 88.62 at baseline to 84.90 at 12 months in the TAM group. The mean score of the appetite loss scale in the TOR group was slightly higher than that in the TAM group, with marginal significance (14.73 vs 5.56 , $p=0.051)$, at the 6th month of follow-up.

\section{Discussion}

Our prospective study found that in HR-positive premenopausal breast cancer patients, the incidence of
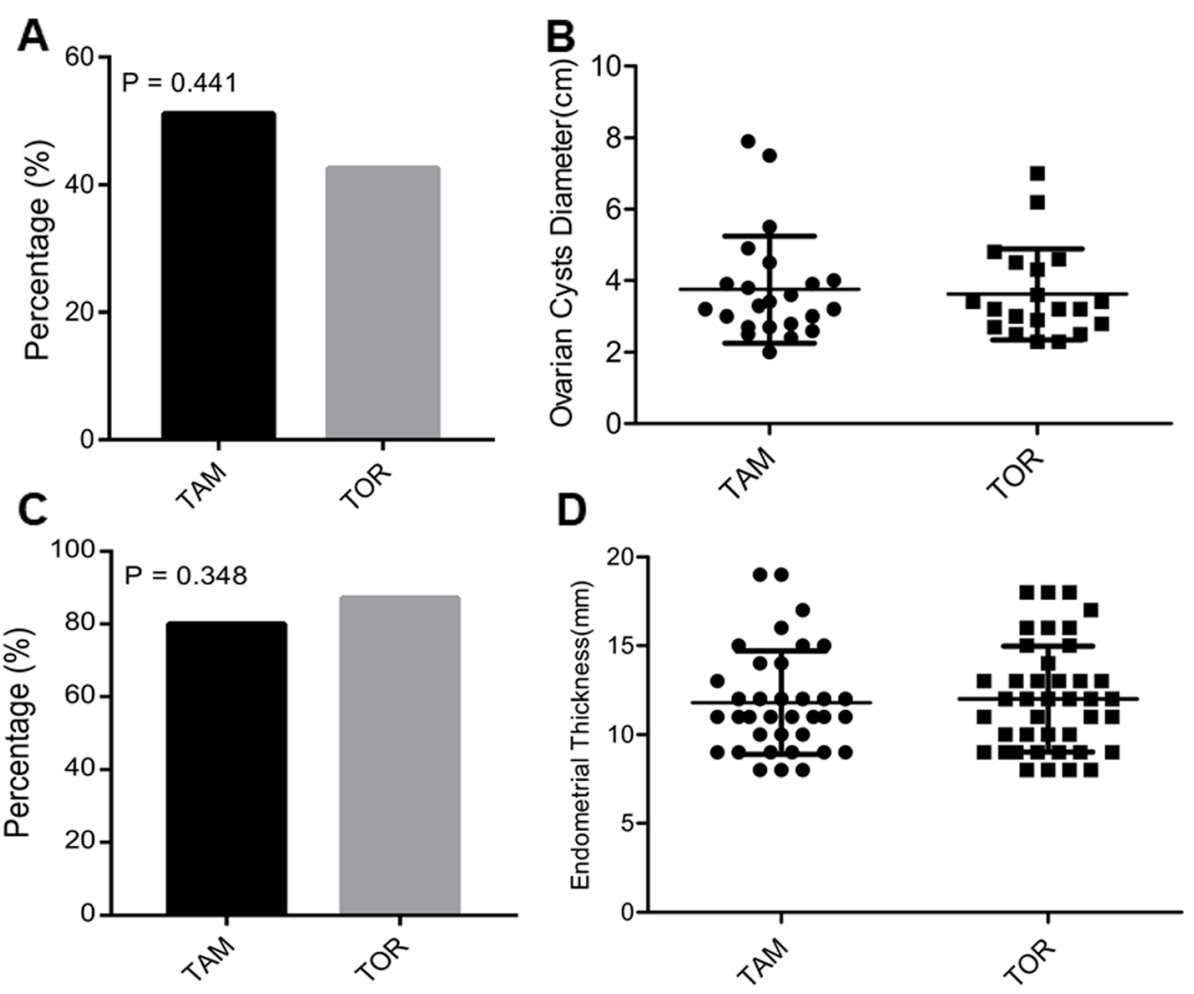

Fig. 2 Incidences of ovarian cysts and endometrial thickening in premenopausal women treated with tamoxifen or toremifene. a Percentage of ovarian cysts (largest diameter $\geq 2 \mathrm{~cm}$ ); $\mathbf{b}$ Mean values of ovarian cysts diameters in two groups. c Percentage of endometrial thickening (endometrial thickness $\geq 8 \mathrm{~mm}$ ) in two groups; d Mean values of endometrial thickness for patients with endometrial thickening in two groups. Abbreviation: TAM tamoxifen, TOR toremifene 


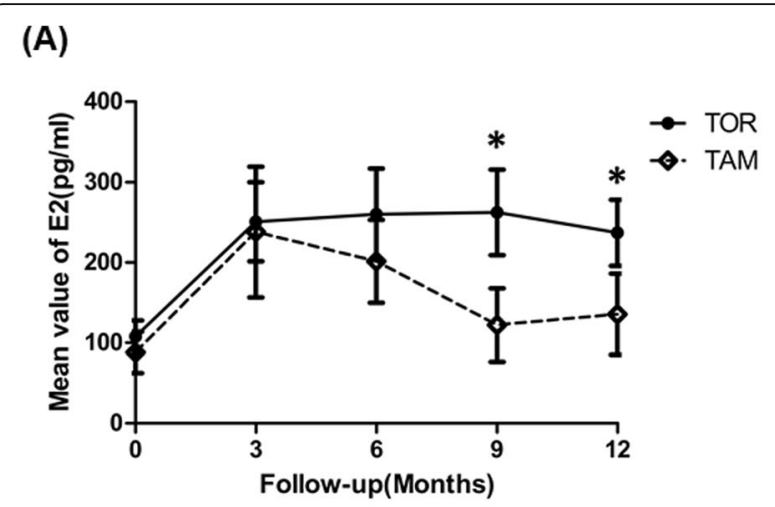

(B)

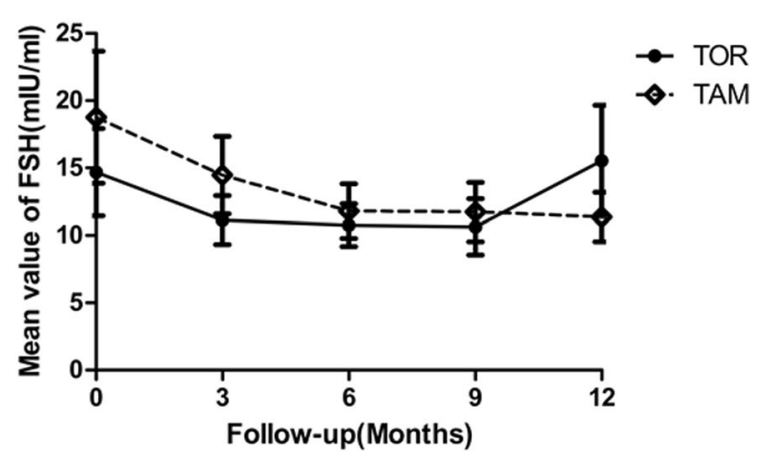

(C)

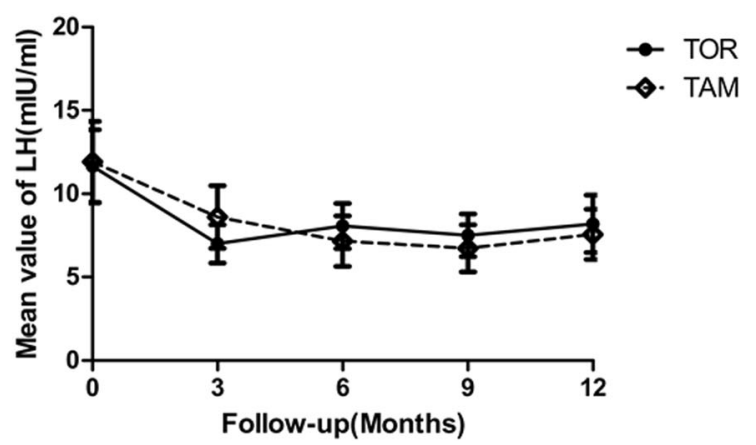

Fig. 3 Mean values $( \pm S E$ ) of serum E2(a), FSH(b) and $\mathrm{LH}(\mathbf{c})$ and in patients treated with toremifene and tamoxifen at each follow-up. * $p<0.05$. Abbreviation: TAM tamoxifen, TOR toremifene, E2 estradiol, FSH follicle stimulating hormone, LH luteinizing hormone

ovarian cysts was similar between the TOR and TAM groups. Additionally, other side effects, such as endometrial thickening, menopausal symptoms, fatty liver, and quality of life, were all comparable between the two groups.

TAM is the dominant endocrine therapy for premenopausal breast cancer patients; however, approximately $42 \%$ of patients discontinue treatment within the first 2 years for different reasons [20]. In addition to its antioestrogenic effects, TAM has a mild oestrogenic effect that depends on the end organ, endogenous oestrogen levels and dose [8]. Gynaecologic symptoms and side
Table 2 Mean values of mKMl in two groups at each follow-up

\begin{tabular}{|c|c|c|c|c|c|}
\hline \multirow[t]{2}{*}{ Time } & \multicolumn{2}{|c|}{ TOR } & \multicolumn{2}{|c|}{ TAM } & \multirow{2}{*}{$\begin{array}{l}p \text { - } \\
\text { value }\end{array}$} \\
\hline & $\mathrm{N}$ & Mean (SD) & $\mathrm{N}$ & Mean (SD) & \\
\hline Baseline & 46 & $10.91(7.34)$ & 45 & $9.53(6.40)$ & 0.530 \\
\hline 3-month follow-up & 45 & $11.78(8.31)$ & 37 & $13.00(6.97)$ & 0.285 \\
\hline 6-month follow-up & 44 & $13.00(8.92)$ & 39 & $12.49(6.31)$ & 0.949 \\
\hline 9-month follow-up & 43 & 10.79(8.33) & 35 & 13.03(7.01) & 0.165 \\
\hline 12-month follow-up & 40 & $12.70(8.81)$ & 34 & $11.59(6.08)$ & 0.761 \\
\hline
\end{tabular}

Abbreviations: $m K M I$ Modified Kupperman Menopausal Index, SD Standard deviation, TAM Tamoxifen, TOR Toremifene

${ }^{*} p<0.05$ was considered statistically significant

effects on the ovary and uterus are the most common adverse events in patients receiving SERMs [5]. TOR is another nonsteroidal triphenylethylene selective ER modulator and has similar efficacy in patients with breast cancer [14, 21]. A previous meta-analysis showed that TOR and TAM have similar severe adverse events between peri- or postmenopausal patients but that TOR may cause less vaginal bleeding, fewer headaches and fewer thromboembolic events $[14,21]$. However, there is no prospective clinical study that evaluates and compares the adverse effects of TOR and TAM in premenopausal women.

Ovarian cysts are common in premenopausal women treated with TAM and are associated with higher serum E2, younger age and the absence of high-dose chemotherapy [22]. Between different studies, the incidence of ovarian cysts in premenopausal patients ranges from 17 to $49 \%$, and these rates are higher than that in postmenopausal women $[8,22]$. There are few reports on ovarian cysts in patients treated with TOR. Our results revealed that the incidence of ovarian cysts detected by TVU was similar between the TOR and TAM patient groups, though slightly higher numerically in the TAM group. We observed that the incidence of ovarian cysts was very high in premenopausal patients treated with SERMs: 42.6 and $51.5 \%$ in the TOR and TAM groups, respectively.

Treatment with TAM can increase plasma E2 concentrations by interfering with normal negative pituitary feedback mechanisms $[23,24]$. A previous study revealed that circulating levels of FSH and LH remained in the normal range in premenopausal patients who received TAM, while the level of E2 was elevated one- to threefold [25]. Our study had the same results: plasma E2 increased significantly with TOR or TAM treatment, and the levels of FSH and $\mathrm{LH}$ remained in the normal range. However, we found that the mean E2 values in the TAM group decreased after the second follow-up examination and were lower than those in the TOR group.

Because of its oestrogen-like effects on the uterus, TAM also triggers endometrial proliferation [26]. In previous studies, endometrial thickness was significantly 
Table 3 Quality of life assessment based on EORTC-QLQ-C30

\begin{tabular}{|c|c|c|c|c|c|c|c|c|c|}
\hline \multirow[t]{3}{*}{ EORTC-QLQ-C30 scales } & \multicolumn{2}{|l|}{ Baseline } & \multirow{3}{*}{$\begin{array}{l}p- \\
\text { value }\end{array}$} & \multicolumn{2}{|c|}{ 6-months follow-up } & \multirow{3}{*}{$\begin{array}{l}p- \\
\text { value }\end{array}$} & \multicolumn{2}{|c|}{ 12-months follow-up } & \multirow{3}{*}{$\begin{array}{l}p- \\
\text { value }\end{array}$} \\
\hline & Toremifene & Tamoxifen & & Toremifene & Tamoxifen & & Toremifene & Tamoxifen & \\
\hline & Mean (SD) & Mean (SD) & & Mean (SD) & Mean (SD) & & Mean (SD) & Mean (SD) & \\
\hline \multicolumn{10}{|l|}{ Functional scales } \\
\hline Physical functioning & $86.05(12.75)$ & $83.58(11.56)$ & 0.276 & $88.68(12.13)$ & $88.33(13.46)$ & 0.968 & $90.10(11.36)$ & $91.25(9.79)$ & 0.849 \\
\hline Role functioning & $73.64(21.59)$ & $79.27(20.68)$ & 0.211 & $84.50(20.70)$ & $81.48(21.37)$ & 0.427 & $89.05(17.59)$ & $86.46(16.09)$ & 0.361 \\
\hline Emotional functioning & $70.93(20.92)$ & $81.71(18.75)$ & 0.017 & $76.16(22.76)$ & $80.56(13.21)$ & 0.667 & $79.76(19.83)$ & $82.81(13.04)$ & 0.798 \\
\hline Cognitive functioning & $82.56(18.17)$ & $88.62(12.04)$ & 0.138 & $83.72(16.46)$ & $85.19(13.08)$ & 0.932 & $84.29(21.37)$ & $84.90(18.14)$ & 0.825 \\
\hline Social functioning & $72.48(22.97)$ & $78.46(20.50)$ & 0.291 & $82.17(20.70)$ & $85.64(19.17)$ & 0.469 & $89.52(15.17)$ & $87.50(16.40)$ & 0.543 \\
\hline \multicolumn{10}{|l|}{ Symptom scales } \\
\hline Fatigue & $31.52(19.39)$ & $25.20(14.70)$ & 0.080 & $25.06(19.86)$ & $25.00(14.64)$ & 0.763 & $23.17(24.16)$ & $18.75(16.80)$ & 0.664 \\
\hline Nausea/vomitting & $3.10(11.65)$ & $5.28(13.14)$ & 0.198 & $3.10(8.34)$ & $1.39(6.14)$ & 0.229 & $1.90(6.73)$ & $2.08(7.02)$ & 0.909 \\
\hline Pain & $22.87(22.13)$ & $16.67(13.94)$ & 0.292 & $17.44(18.17)$ & $12.5(14.57)$ & 0.215 & $12.38(13.61)$ & $16.15(16.11)$ & 0.368 \\
\hline Dyspnoea & $18.60(28.45)$ & $12.19(17.89)$ & 0.211 & 13.18(20.75) & $12.04(16.24)$ & 0.924 & $15.24(21.91)$ & $15.63(20.71)$ & 0.850 \\
\hline Insomnia & $13.17(25.34)$ & $28.46(26.42)$ & 0.353 & $30.23(34.74)$ & $28.70(21.31)$ & 0.620 & $30.48(33.70)$ & $23.96(25.73)$ & 0.571 \\
\hline Appetite loss & $18.60(28.45)$ & $9.76(17.07)$ & 0.200 & $14.73(22.19)$ & $5.56(12.60)$ & 0.051 & $11.43(19.71)$ & $5.21(12.30)$ & 0.180 \\
\hline Constipation & $13.18(25.34)$ & $12.20(19.37)$ & 0.655 & $16.28(28.52)$ & $6.49(17.49)$ & 0.080 & 19.82(33.75) & $13.54(20.50)$ & 0.845 \\
\hline Diarrhoea & $6.20(13.12)$ & $7.32(19.02)$ & 0.898 & $3.88(10.81)$ & $5.56(14.91)$ & 0.733 & $4.50(16.03)$ & $2.08(8.20)$ & 0.728 \\
\hline
\end{tabular}

higher in postmenopausal patients treated with TAM than in control subjects $[27,28]$. Severe gynaecologic adverse events, such as endometrial polyps, hyperplasia and endometrial cancer, induced by TAM were increased by $2-4$-fold compared to no TAM treatment [29]. Long follow-up studies have shown that 5 years of adjuvant TAM brings about a $2-3 \%$ risk of endometrial cancer over 15 years; however, there is little risk of endometrial cancer in premenopausal women [4]. All patients in our study were premenopausal women, and the follow-up time was only 1 year; no patient underwent endometrial biopsy due to endometrial thickening, and no endometrial cancer was found. However, the proportions of endometrial thickening in the TAM and TOR groups were approximately 80 and $87.2 \%$, respectively, although there was no significant difference between the two groups. The measurement of endometrial thickness was difficult as the menstrual pattern changes in premenopausal patients taking TAM [23, 30]. For patients with a regular menstrual cycle, TVU was carried out 1 week after menses every 3 months. For patients with irregular menstrual cycles, oligomenorrhea or amenorrhea, TVU was carried out every 3 months routinely. At baseline, 36 patients (39.1\%) already had endometrial thickening. A previous study of patients in Japan showed that the median endometrial thickness was $8.6 \mathrm{~mm}$ [31]. As the cut-off of endometrial thickness was $8 \mathrm{~mm}$ in our study, we observed high rates of endometrial thickening.

As TAM treatment also influences ovarian function, approximately two-thirds of patients develop oligomenorrhea or amenorrhea, which leads to side effects such as hot flashes [23]. We used the mKMI to evaluate menopausal symptoms. At baseline, the mean mKMI scores were 10.91 in the TOR group and 9.53 in the TAM group. During follow-up, the mean scores of the two groups increased slightly compared with the baseline scores. No significant differences between the two groups were observed at any of the follow-up times. In terms of the severity grade, both the patients treated with TOR and those treated with TAM had mild menopausal symptoms.

Non-alcoholic fatty liver disease (NAFLD) is another common adverse event caused by TAM, and may be related to increasing serum triglycerides, inhibition of mitochondrial $\beta$-oxidation of fatty acids and suppression of oestrogen synthesis [10]. Previous studies revealed that the NAFLD rates in patients taking TAM were approximately 46 to $48 \%$ [10,32]. In patients treated with TOR, the incidence of NAFLD was only $7.7 \%$, as reported by a study from Japan [33]. Our results showed that in the first year of endocrine therapy, $31.9 \%$ of patients in the TOR group and $26.7 \%$ of patients in the TAM group had NAFLD, and these incidences were slightly lower than those of previous reports. However, we did not observe the superiority of TOR over TAM. In addition, some studies revealed that prevalence of NAFLD was ranging from 25 to $44 \%$ in China [34]. It was a confusing factor that we could not make the comparison simply.

Quality of life was evaluated by means of the EORTCQLQ-C30 questionnaire, and there were no significant 
differences between the two groups at any of the followup times. We also observed an increasing tendency in the mean scores of the functional scales and a slight decreasing tendency in the mean scores of the symptom scales compared with the baseline, indicating that quality of life was improved with both TOR and TAM treatment. Although controversial, the results of other studies support this phenomenon, wherein quality of life at baseline is worse after surgery or chemotherapy [35, 36].

This study has some limitations. The current study is an open-label study, and block randomization may result in selection bias when the study groups are unmasked. Second, gynaecological side effects in patients are also influenced by other factors, such as chemotherapy and radiotherapy. Third, the follow-up time of this study was only 1 year and was too short for the detection of some adverse events, such as endometrial cancer. Forth, Sex hormones were analysed in less than half of the patients.

\section{Conclusions}

In conclusion, our prospective study revealed that treatment with TOR or TAM results in similar side effects in terms of the female genital system and quality of life in premenopausal women with breast cancer. The incidence rates of ovarian cysts were similar between the TOR and TAM groups. Other side effects, such as endometrial thickening, menopausal symptoms and fatty liver, were comparable between the two groups. TOR is a safe alternative to TAM as an adjuvant treatment for HR-positive premenopausal breast cancer.

\section{Supplementary information}

Supplementary information accompanies this paper at https://doi.org/10. 1186/s12885-020-07156-X.

Additional file 1 Table S1. Mean values of FSH, LH and E2 in two groups at each follow-up.

\section{Abbreviations}

HR: Hormonal receptor; TOR: Toremifene; TAM: Tamoxifen; mKMI: Modified Kupperman Menopausal index; SERM: Selective estrogen receptor modulator; ER: Estrogen receptor; PR: Progesterone receptor; HER-2: Human epidermal growth factor receptor-2; ECOG: Eastern Cooperative Oncology Group; ALT: Alanine aminotransferase; AST: Aspartate aminotransferase; ULN: Upper limit of normal range; TVU: Transvaginal ultrasound; FISH: Fluorescence in situ hybridization; E2: Plasma estradiol; FSH: Follicle stimulating hormone; LH: Luteinizing hormone; EORTC: European Organization for Research and Treatment of Cancer; SD: Standard deviation; SE: Standard error; NAFLD: Nonalcoholic fatty liver disease

\section{Acknowledgements}

The authors gratefully thank all the patients participating in this study and the staff at our center for their work and support of this study.

\section{Authors' contributions}

KWS played an important role in the study design. JH played an important role in the patients recruiting, interpreting the results and manuscript written. XSC played an important role in the study design, interpreting the results and manuscript written. $\mathrm{JHH}$ was responsible for the study design, the patients recruiting and follow-up. LLS, SJZ, WQG, JYW, OH, JRH, LZ, WGC and YFL contributed to the patients' data collection and follow-up. All authors reviewed and approved the final draft.

\section{Funding}

This study was financially supported by grants from National Natural Science Foundation of China (Grant Number: 81472462 and 81772797), Medical Guidance Foundation of Shanghai Municipal Science and Technology Commission (15411966400), Shanghai Municipal Education Commission Gaofeng Clinical Medicine Grant Support (20172007) and Guangci Distinguished Young Scholars Training Program (GCQN-2018-B11). The funding bodies had no role in study design, collection, analysis, or interpretation of data, or in writing the manuscript.

\section{Availability of data and materials}

The datasets during and/or analysed during the current study are available from the corresponding author on reasonable request.

\section{Ethics approval and consent to participate}

The protocol was reviewed and approved by the independent ethical committee/institutional review board of Shanghai Ruijin Hospital affiliated with Shanghai Jiao Tong University School of Medicine. All procedures performed in studies involving human participants were in accordance with the ethical standards of the committee and with the 1964 Helsinki declaration and its later amendments or comparable ethical standards. The written informed consents were provided by all patients before inclusion in the study.

\section{Consent for publication}

Not applicable.

\section{Competing interests}

The authors declare that they have no competing interests.

Received: 9 June 2019 Accepted: 9 July 2020

Published online: 16 July 2020

References

1. Waks AG, Winer EP. Breast cancer treatment: a review. JAMA. 2019;321(3): 288-300.

2. Early Breast Cancer Trialists' Collaborative Group (EBCTCG), Davies C, Godwin J, et al. Relevance of breast cancer hormone receptors and other factors to the efficacy of adjuvant tamoxifen: patient-level meta-analysis of randomised trials. Lancet. 2011;378(9793):771-84.

3. Curigliano G, Burstein HJ, E PW, Gnant M, Dubsky P, Loibl S, et al. Deescalating and escalating treatments for early-stage breast cancer: the St. Gallen international expert consensus conference on the primary therapy of early breast cancer. Ann Oncol 2017. 2017;28(8):1700-12.

4. Davies C, Pan H, Godwin J, Gray R, Arriagada R, Raina V, et al. Long-term effects of continuing adjuvant tamoxifen to 10 years versus stopping at 5 years after diagnosis of oestrogen receptor-positive breast cancer: ATLAS, a randomised trial. Lancet. 2013;381(9869):805-16.

5. Lorizio W, Wu AH, Beattie MS, Rugo H, Tchu S, Kerlikowske K, et al. Clinical and biomarker predictors of side effects from tamoxifen. Breast Cancer Res Treat. 2012;132(3):1107-18.

6. Inal MM, Incebiyik A, Sanci M, Yildirim Y, Polat M, Pilanci B, et al. Ovarian cysts in tamoxifen-treated women with breast cancer. Eur J Obstet Gynecol Reprod Biol. 2005;120(1):104-6.

7. Group BIGC, Mouridsen H, Giobbie-Hurder A, Goldhirsch A, Thurlimann B, Paridaens $\mathrm{R}$, et al. Letrozole therapy alone or in sequence with tamoxifen in women with breast cancer. N Engl J Med. 2009;361(8):766-76.

8. Metindir J, Aslan S, Bilir G. Ovarian cyst formation in patients using tamoxifen for breast cancer. Jpn J Clin Oncol. 2005;35(10):607-11.

9. Kusama M, Kaise H, Nakayama S, Ota D, Misaka T, Aoki T. Crossover trial for lipid abnormality in postmenopausal breast cancer patients during selective estrogen receptor modulators (SERMs) administrations. Breast Cancer Res Treat. 2004:88(1):9-16.

10. Yang YJ, Kim KM, An JH, Lee DB, Shim JH, Lim YS, et al. Clinical significance of fatty liver disease induced by tamoxifen and toremifene in breast cancer patients. Breast. 2016;28:67-72.

11. Vogel $C L$, Johnston MA, Capers C, Braccia D. Toremifene for breast cancer: a review of 20 years of data. Clin Breast Cancer. 2014;14(1):1-9. 
12. International Breast Cancer Study G, Pagani O, Gelber S, Price K, Zahrieh D, Gelber $\mathrm{R}$, et al. Toremifene and tamoxifen are equally effective for earlystage breast cancer: first results of international breast cancer study group trials 12-93 and 14-93. Ann Oncol. 2004;15(12):1749-59.

13. Lewis JD, Chagpar AB, Shaughnessy EA, Nurko J, McMasters K, Edwards MJ. Excellent outcomes with adjuvant toremifene or tamoxifen in early stage breast cancer. Cancer. 2010;116(10):2307-15.

14. Zhou WB, Ding Q, Chen L, Liu XA, Wang S. Toremifene is an effective and safe alternative to tamoxifen in adjuvant endocrine therapy for breast cancer: results of four randomized trials. Breast Cancer Res Treat. 2011; 128(3):625-31.

15. Lan B, Ma F, Chen S, et al. Toremifene, rather than tamoxifen, might be a better option for the adjuvant endocrine therapy in CYP2D6*10T/T genotype breast cancer patients in China. Int J Cancer. 2018;143(10):2499504.

16. Gu R, Jia W, Zeng Y, Rao N, Hu Y, Li S, et al. A comparison of survival outcomes and side effects of toremifene or tamoxifen therapy in premenopausal estrogen and progesterone receptor positive breast cancer patients: a retrospective cohort study. BMC Cancer. 2012;12:161.

17. Fan JG, Jia JD, Li YM, Wang BY, Lu LG, Shi JP, et al. Guidelines for the diagnosis and management of nonalcoholic fatty liver disease: update 2010: (published in Chinese on Chinese journal of hepatology 2010; 18:163-166). J Dig Dis. 2011;12(1):38-44.

18. Yang R, Zhou Y, Li C, Tao M. Association between pulse wave velocity and hot flashes/sweats in middle-aged women. Sci Rep. 2017;7(1):13854

19. Finck C, Barradas S, Zenger M, Hinz A. Quality of life in breast cancer patients: associations with optimism and social support. Int J Clin Health Psychol. 2018;18(1):27-34.

20. Cluze C, Rey D, Huiart L, BenDiane MK, Bouhnik AD, Berenger C, et al. Adjuvant endocrine therapy with tamoxifen in young women with breast cancer: determinants of interruptions vary over time. Ann Oncol. 2012;23(4): 882-90

21. Ye QL, Zhai ZM. Toremifene and tamoxifen have similar efficacy in the treatment of patients with breast cancer: a meta-analysis of randomized trials. Mol Biol Rep. 2014;41(2):751-6.

22. Mourits MJ, de Vries EG, Willemse PH, ten Hoor KA, Hollema H, Sluiter WJ, et al. Ovarian cysts in women receiving tamoxifen for breast cancer. $\mathrm{Br}$ J Cancer. 1999:79(11-12):1761-4.

23. Berliere M, Duhoux FP, Dalenc F, Baurain JF, Dellevigne L, Galant C, et al. Tamoxifen and ovarian function. PLoS One. 2013;8(6):e66616.

24. Shapiro $\mathrm{CL}$, Recht $\mathrm{A}$. Side effects of adjuvant treatment of breast cancer. $\mathrm{N}$ Engl J Med. 2001;344(26):1997-2008.

25. Jordan VC, Fritz NF, Langan-Fahey S, Thompson M, Tormey DC. Alteration of endocrine parameters in premenopausal women with breast cancer during long-term adjuvant therapy with tamoxifen as the single agent. J Natl Cancer Inst. 1991;83(20):1488-91.

26. Gerber B, Krause A, Muller H, Reimer T, Kulz T, Makovitzky J, et al. Effects of adjuvant tamoxifen on the endometrium in postmenopausal women with breast cancer: a prospective long-term study using transvaginal ultrasound. J Clin Oncol. 2000;18(20):3464-70

27. Cohen I, Azaria R, Shapira J, Yigael D, Tepper R. Significance of secondary ultrasonographic endometrial thickening in postmenopausal tamoxifentreated women. Cancer. 2002;94(12):3101-6.

28. Lee S, Kim YH, Kim SC, Joo JK, Seo DS, Kim KH, et al. The effect of tamoxifen therapy on the endometrium and ovarian cyst formation in patients with breast cancer. Obstet Gynecol Sci. 2018;61(5):615-20.

29. Kim HS, Jeon YT, Kim YB. The effect of adjuvant hormonal therapy on the endometrium and ovary of breast cancer patients. J Gynecol Oncol. 2008; 19(4):256-60.

30. Chien AJ, Duralde E, Hwang R, Tsung K, Kao CN, Rugo HS, et al. Association of tamoxifen use and ovarian function in patients with invasive or preinvasive breast cancer. Breast Cancer Res Treat. 2015;153(1):173-81.

31. Tsuda H, Ito YM, Todo Y, Iba T, Tasaka K, Sutou Y, et al. Measurement of endometrial thickness in premenopausal women in office gynecology. Reprod Med Biol. 2018;17(1):29-35.

32. Chang HT, Pan HJ, Lee CH. Prevention of tamoxifen-related nonalcoholic fatty liver disease in breast cancer patients. Clin Breast Cancer. 2018;18(4): e677-85.

33. Hamada N, Ogawa Y, Saibara T, Murata Y, Kariya S, Nishioka A, et al. Toremifene-induced fatty liver and NASH in breast cancer patients with breast-conservation treatment. Int J Oncol. 2000;17(6):1119-23.
34. Younossi ZM, Koenig AB, Abdelatif D, Fazel Y, Henry L, Wymer M. Global epidemiology of nonalcoholic fatty liver disease-meta-analytic assessment of prevalence, incidence, and outcomes. Hepatology. 2016;64(1):73-84.

35. Boehm DU, Lebrecht A, Eckhardt T, Albrich S, Schmidt M, Siggelkow W, et al. Quality of life and adjuvant tamoxifen treatment in breast cancer patients. Eur J Cancer Care (Engl). 2009;18(5):500-6.

36. van Nes JG, Fontein DB, Hille ET, Voskuil DW, van Leeuwen FE, de Haes JC, et al. Quality of life in relation to tamoxifen or exemestane treatment in postmenopausal breast cancer patients: a tamoxifen Exemestane adjuvant multinational (TEAM) trial side study. Breast Cancer Res Treat. 2012;134(1): 267-76.

\section{Publisher's Note}

Springer Nature remains neutral with regard to jurisdictional claims in published maps and institutional affiliations.
Ready to submit your research? Choose BMC and benefit from:

- fast, convenient online submission

- thorough peer review by experienced researchers in your field

- rapid publication on acceptance

- support for research data, including large and complex data types

- gold Open Access which fosters wider collaboration and increased citations

- maximum visibility for your research: over $100 \mathrm{M}$ website views per year

At BMC, research is always in progress.

Learn more biomedcentral.com/submissions 